\title{
Host Defense against Systemic Infection with Streptococcus pneumoniae Is Impaired in E-, P-, and E-/P-Selectin-deficient Mice
}

\author{
Flor M. Munoz, ${ }^{\star}$ Edith P. Hawkins, ${ }^{\ddagger}$ Daniel C. Bullard, ${ }^{\S \uparrow}$ Arthur L. Beaudet, ${ }^{\star \S \|}$ and Sheldon L. Kaplan ${ }^{\star}$ \\ ${ }^{*}$ Department of Pediatrics, ${ }^{\ddagger}$ Department of Pathology, and ${ }^{\S}$ Department of Molecular and Human Genetics, Baylor College of Medicine, \\ and ${ }^{\|}$Howard Hughes Medical Institute, Houston, Texas 77030; and "Department of Comparative Medicine, University of Alabama, \\ Birmingham, Alabama 35294
}

\begin{abstract}
Endothelial selectins mediate rolling of leukocytes on endothelium, a crucial step for leukocyte firm adhesion and emigration into sites of tissue injury and infection. To characterize the role of the endothelial selectins during bacterial sepsis in vivo, Streptococcus pneumoniae $\left(1-10 \times 10^{6}\right.$ colony-forming units) was inoculated intraperitoneally into wild-type mice and mice with E-, P-, or E-/P-selectin deficiencies. Mice were followed $\mathbf{1 0} \mathrm{d}$ for morbidity, survival, clearance of bacteremia, and leukocyte migration to the peritoneal cavity and organs $48 \mathrm{~h}$ after infection. All selectin-deficient mice showed a more pronounced morbidity, a significantly higher mortality associated with persistent bacteremia, and a higher bacterial load when compared with wild-type mice. These differences were most remarkable in the E-selectin-deficient mice, which showed the highest rate of mortality and bacteremia $(P \leq 0.0001)$. No significant differences were observed among the groups in the inflammatory response present in the peritoneal cavity, brain, liver, spleen, or kidney at $48 \mathrm{~h}$ after inoculation. Extensive hepatic and splenic necrosis and thrombosis were noted in E- and P-selectin-deficient mice. Although the absence of endothelial selectins did not substantially impair leukocyte emigration to sites of infection $48 \mathrm{~h}$ after pneumococcal sepsis, it resulted in increased mortality and a higher bacterial load in the bloodstream of selectin-deficient mice. These results demonstrate a definitive phenotypic abnormality in E-selectin-deficient mice, and suggest that E- and $P$-selectin are important in the host defense against $S$. pneumoniae infection. (J. Clin. Invest. 1997. 100:2099-2106.) Key words: adhesion molecules $•$ E-selectin $\bullet$ infection $\bullet$ Streptococcus pneumoniae $\cdot$ mice
\end{abstract}

\section{Introduction}

The interaction between leukocytes and endothelial adhesion molecules is a key factor in the generation of effective inflammatory and immune responses against injury and infection $(1$,

Address correspondence to Sheldon L. Kaplan, M.D., Texas Children's Hospital, Clinical Care Center, Suite 1150 MC 3-2371, 6621 Fannin Street, Houston, TX 77030-2399. Phone: 713-770-4330; FAX: 713-770-4347; E-mail: skaplan@bcm.tmc.edu

Received for publication 11 April 1997 and accepted in revised form 22 August 1997.

J. Clin. Invest.

(C) The American Society for Clinical Investigation, Inc. 0021-9738/97/10/2099/08 \$2.00

Volume 100, Number 8, October 1997, 2099-2106

http://www.jci.org
2). In the systemic circulation, the initial step in the adhesion cascade consists of the tethering and rolling of leukocytes along the postcapillary venular endothelium, and is mediated by the interactions of the selectin molecules and their sialylated carbohydrate ligands (3-6). This reversible step is followed by firm adhesion and emigration, mediated by the interaction of the $\beta 2$ integrin molecules (CD18/CD11 heterodimers) and their immunoglobulin-like ligands (intercellular adhesion molecule-1 [ICAM-1] ${ }^{1}$ and others).

The selectin family consists of three cell surface molecules expressed by leukocytes (L-selectin), platelets (P-selectin), and vascular endothelium (E- and P-selectin). All three selectins have been shown to mediate leukocyte rolling using intravital microscopy or in vitro flow chambers $(5,6)$. L-selectin, constitutively expressed by most circulating leukocytes and shed after leukocyte activation, also functions as a lymphocyte homing receptor in lymph nodes $(7,8)$. E-selectin transcription and expression at the endothelial cell surface are induced within several hours after activation with proinflammatory mediators $(9,10)$. P-selectin is preformed and stored in the $\alpha$-granules of platelets, and in secretory granules (Weibel-Palade bodies) in endothelial cells. Upon activation, P-selectin is mobilized immediately from these intracellular stores and expressed on the cell surface. P-selectin also mediates the adhesion of platelets to monocytes and neutrophils $(11,12)$ and is required for neutrophil accumulation within thrombi, which is important for fibrin deposition and thrombogenesis $(13,14)$.

Initial investigations of the role of E- and P-selectin in inflammatory responses were performed using inhibitors such as $\mathrm{mAbs}$ in experimental models of inflammation. More recently, studies of mice with E- and P-selectin mutations, generated using gene targeting techniques in embryonic stem cells, have established further the important functions of these molecules in leukocyte rolling and inflammation (5). Mice with single E- or $\mathrm{P}$-selectin deficiencies are not prone to spontaneous disease or lethal infections under normal laboratory housing conditions. P-selectin-deficient mice exhibit slight leukocytosis and neutrophilia, severely diminished early (2-4 h) leukocyte rolling, delayed early (2-4 h) recruitment of neutrophils to the peritoneal cavity after bacterial or chemically induced peritonitis, and prolonged bleeding times (15-18). E-selectin-deficient mice have not been shown to develop inflammatory defects in similar models, unless P-selectin is blocked simultaneously (19). However, a defect in slow leukocyte rolling of granulocytes in TNF- $\alpha$-stimulated venules was demonstrated recently in E-selectin-deficient mice (20). Mice with null mutations of both E- and P-selectin develop a phenotype of leukocyte adhesion deficiency characterized by increased susceptibility to mu-

1. Abbreviations used in this paper: ANC, absolute neutrophil counts; CSF, cerebrospinal fluid; ICAM-1, intercellular adhesion molecule-1; WBC, white blood cell. 
cocutaneous infections, plasmacytosis, hypergammaglobulinemia, severe deficiencies of leukocyte rolling, and absence of early $(2-4 \mathrm{~h})$ neutrophil emigration during bacterial or chemically induced peritonitis $(21,22)$. Altered hematopoiesis with significant leukocytosis and splenomegaly are also observed (22).

These studies suggested initially that E- and P-selectin serve redundant functions, although $\mathrm{P}$-selectin appears to play a predominant role in mediating leukocyte rolling and emigration $(17,23-25)$. In this study, we delineate further the role of the endothelial selectins in vivo by inducing systemic Streptococcus pneumoniae infection in wild-type mice and mice with single E-, P-, or double E-/P-selectin deficiencies. We hypothesize that deficiencies of the endothelial selectins ultimately impair the host's defense mechanisms against disseminated pneumococcal infection, resulting in increased morbidity and mortality as well as in defective emigration of leukocytes to sites of infection.

\section{Methods}

Animals. 8-wk-old mice with specific selectin deficiencies or wildtype mice were used in serial experiments. In each experiment, up to 10 animals of two or more mutant groups and their controls were analyzed. E-, P-, and E-/P-selectin-deficient mice were generated as described previously $(17,18,21)$. All animals were from a mixed $129 / \mathrm{Sv} \times$ C57BL/6 background. Homozygous mutant mice were viable and fertile; weight gain and survival were normal compared with wild-type mice. Because of the young age, double mutants had not developed spontaneous infections before these experiments. Serial serologies from sentinel animals in the colony were consistently negative for common murine viral pathogens. The animals were housed and fed under standard laboratory conditions. Once inoculated, mice were placed in separate cages under an isolation hood.

Bacteria. S. pneumoniae Colvin (serotype 6), isolated from cerebrospinal fluid (CSF) of a child with meningitis and unilateral severe hearing loss at Texas Children's Hospital, was frozen at $-80^{\circ} \mathrm{C}$ in trypticase soy broth with $10 \%$ glycerol ( $\mathrm{pH} 7.3$ ) after a single passage from the original culture. For each experiment, an aliquot of $S$. pneumoniae was grown overnight on a blood agar plate at $35^{\circ} \mathrm{C}$. Several loopfuls of the culture were inoculated into $10 \mathrm{ml}$ of $2 \%$ laked horse blood broth and incubated for $6 \mathrm{~h}$. Pellets were obtained by centrifugation at 10,000 $\mathrm{g}$ for $10 \mathrm{~min}$. The pellets were washed once in PBS, $\mathrm{pH} 7.4$, and resuspended in PBS to a final concentration of $1-10 \times 10^{8}$ $\mathrm{CFU} / \mathrm{ml}$, confirmed by colony count. The suspensions were diluted $1: 10$ with PBS before inoculation.

Animal inoculation. Mice were inoculated intraperitoneally with a single $0.1-\mathrm{ml}$ dose $\left(1-10 \times 10^{6} \mathrm{CFU} / \mathrm{ml}\right)$ of $S$. pneumoniae. The final concentration was confirmed by colony count. Baseline weight determinations were obtained on all animals before inoculation.

Peripheral blood leukocyte counts and cultures. Baseline white blood cell (WBC) counts and absolute neutrophil counts (ANC) were obtained on all animals. Blood $(10 \mu \mathrm{l}$ for each) was obtained by tailvein nick for WBC count (Coulter Electronics Ltd., Luton, UK), and differential was obtained by smears stained with differential hematologic stain (Neat Stain; Midlantic Biomedical, Inc., Paulsboro, NJ). The percentage of neutrophils was determined by counting 100 cells under oil immersion. Similarly, blood $(10 \mu \mathrm{l})$ was obtained using sterile technique for culture by inoculation on blood agar incubated at $35^{\circ} \mathrm{C}$. The degree of bacteremia was characterized by the number of CFU per 10 microliters on the blood culture plate. Culture plates with $>300 \mathrm{CFU} / 10 \mu \mathrm{l}$ were defined as having colonies too numerous to count.

Survival and organ harvest studies. Animals were assigned randomly to survival and organ harvest groups. Those in the survival study were observed daily for $10 \mathrm{~d}$ after inoculation for evidence of disease (decreased level of activity, piloerection, weight loss) and mortality. Blood cultures, WBC count, and ANC were obtained in all survivors every $24 \mathrm{~h}$ for $6 \mathrm{~d}$, and every $48 \mathrm{~h}$ thereafter. Animals in the organ harvest group were killed $48 \mathrm{~h}$ after inoculation by intraperitoneal injection of a lethal dose of sodium pentobarbital. A cardiac puncture was performed with sterile technique to obtain blood for WBC counts, ANC, and culture. Under direct visualization by dissection, $1 \mathrm{ml}$ of sterile $0.9 \%$ sodium chloride solution was injected into the peritoneum for lavage. The peritoneal fluid $(10 \mu \mathrm{l})$ was cultured, and WBC count and ANC were determined by the methods described above. The abdominal cavity was exposed to harvest the left lobe of the liver, a portion of the spleen, and the right kidney. In some animals, CSF was collected by cisterna magna puncture using a 27-gauge microfine insulin needle (Becton Dickinson Labware, Franklin Lakes, NJ) for culture (3-4 $\mu \mathrm{l})$, cell count, and differential. Cell counts were determined by Neubauer hemocytometer (Reichert Ophthalmic Instruments, a division of Leica, Buffalo, NY), and the smears were stained with Neat Stain. The small volume of CSF obtained did not allow for determination of all of these values in the same mice. In all animals, the brain was harvested for histopathology.

Histologic examination. After collection, the organs were fixed in $10 \%$ formaldehyde for $24 \mathrm{~h}$ and embedded in paraffin using standard techniques. Hematoxylin-eosin-stained tissue sections were examined by one investigator (E.P. Hawkins), without knowledge of the genotype or status of the mice. The specimens were examined for the presence of inflammation, bacteria, abscess formation, and necrosis. A scoring system was used, grading the histopathologic findings from 0 (none) to $1+$ (mild), $2+$ (moderate), and 3+ (severe).

Statistical analysis. Survival data were analyzed by Kaplan-Meier using logrank analysis to compare survival curves. Differences in WBC counts, ANC, and the degree of bacteremia were analyzed by one-way ANOVA followed by Student's $t$ test or Rank sum test when indicated. The clearance of bacteremia among survivors (dead or bacteremic versus alive without bacteremia) was analyzed over time using Kaplan-Meier and logrank analysis. The presence of inflammation, necrosis, and thrombosis were analyzed by $\chi^{2}$ or Fisher Exact tests. Values are presented as mean \pm SD. Results were considered significant for $P$ values $<0.05$ (two-tailed).

\section{Results}

Systemic infection. Bacteremia was achieved in $90-100 \%$ of mice in each group at $24 \mathrm{~h}$ (Table I). A higher bacterial load was observed in E-selectin-deficient mice, 222 $\pm 94 \mathrm{CFU} / 10 \mu \mathrm{l}$, than in wild-type mice, $134 \pm 133 \mathrm{CFU} / 10 \mu \mathrm{l}(P=0.005)$. The severity and duration of morbidity were more pronounced in all the mutant groups when compared with wild-type mice. Mutant mice consistently showed signs of decreased activity, piloerection, and neurologic involvement, such as head tilt, spinning, and tremors. Uni- or bilateral panophthalmitis was more common in all the selectin-deficient mice $(8 \%$ or $10 / 122$ mutant mice used in all experiments) when compared with

Table I. Bacteremia and Bacterial Load (mean CFU/10 $\mu$ l) in Wild-Type and Selectin-deficient Mice at $24 \mathrm{~h}$ after Intraperitoneal Inoculation with S. pneumoniae

\begin{tabular}{lcc}
\hline \multicolumn{1}{c}{ Group } & $\begin{array}{c}\text { Number of mice } \\
\text { with bacteremia/n }\end{array}$ & Mean CFU*/10 $\mu \mathrm{l}$ \\
\hline Wild-type & $27 / 30$ & $134 \pm 133$ \\
E-selectin & $29 / 29$ & $222^{\ddagger} \pm 94$ \\
P-selectin & $29 / 31$ & $167 \pm 122$ \\
E-/P-selectin & $28 / 29$ & $139 \pm 126$ \\
\end{tabular}

*Values are expressed as mean \pm SD. ${ }^{\ddagger} P=0.005$. 


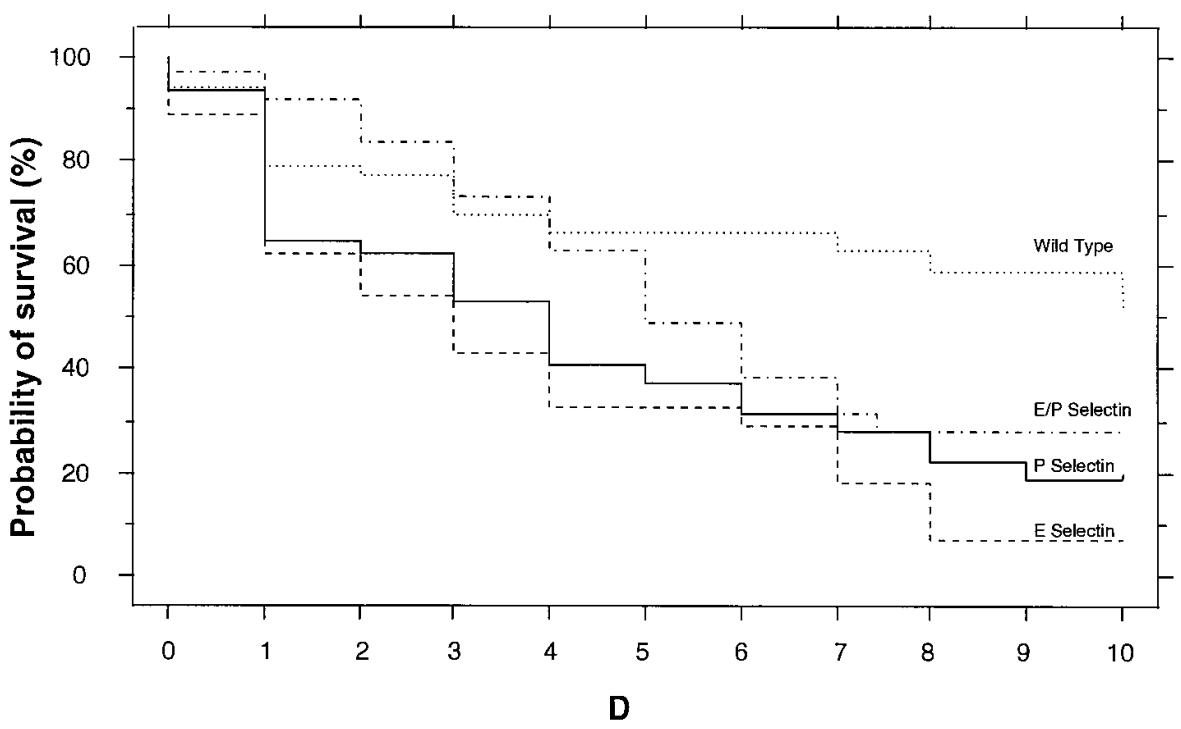

Figure 1. Kaplan-Meier survival analysis of wild-type (dotted line, $n=30$ ) vs. $\mathrm{P}$-selectin- (solid line, $n=31)(P=0.002)$, E-selectin- (dashed line, $n=29)(P \leq$ $0.0001)$, and E-/P-selectin-deficient mice (dotted and dashed line, $n=29)(P=0.13)$, 1-10 d after intraperitoneal inoculation with $S$. pneumoniae. Data were pooled from the organ harvest group for the first $48 \mathrm{~h}(0-48 \mathrm{~h}: n=53$ in wild-type, $n=48$ in $\mathrm{P}-$, and $n=37$ in both E- and E-/P-selectin-deficient groups). wild-type mice ( $2 \%$ or $1 / 53$ mice). At $48 \mathrm{~h}$, all selectin-deficient mice lost $13-16 \pm 5 \%$ of their baseline weight, compared with $6.6 \pm 5 \%$ in wild-type mice $(P \leq 0.0001)$. On day 10 , weight gain was observed in wild-type mice, but P- and E-/P-selectindeficient mice lost $11-14 \%$ of their initial weight $(P \leq 0.05)$, and E-selectin-deficient mice lost $36 \pm 2 \%$ of their baseline weight $(P \leq 0.0001)$.

Survival. Data were pooled from the organ harvest group for the first $48 \mathrm{~h}$, since all animals received the same treatment. Kaplan-Meier survival curves were significantly different among all the groups $(P=0.0003)$ (Fig. 1$)$. A high mortality rate was noted throughout the period of observation in mice with selectin deficiencies when compared with wild-type mice. This was most remarkable in the E-selectin-deficient group, with $7 \%(2 / 29)$ overall survival versus $57 \%$ (17/30) for the wild-type mice $(P \leq 0.0001)$. A survival rate of $19 \%(6 / 31)$ was observed in the P-selectin-deficient group $(P=0.002)$, and $28 \%(8 / 29)$ in the E-/P-selectin-deficient mice $(P=0.13)$. Al- though a slightly higher survival was noted on days $0-5$ after inoculation in the E-/P-selectin-deficient mice, this difference was not statistically significant $(P=0.19$ vs. wild-type mice), and after day 5, significant mortality was observed in this group ( $P=0.003$ vs. wild-type mice). Single E- and P-selectindeficient mice showed a higher mortality rate than double E-/P-selectin mutant mice over the entire period of observation $(P=0.004$ and $P=0.03$, respectively).

Clearance of bacteremia among survivors. Wild-type survivors effectively cleared the bacteremia as early as $48 \mathrm{~h}$ after inoculation, and by day 10 , all $(n=17)$ had sterile blood cultures (Fig. 2). In contrast, $>90 \%$ of mutant survivors were bacteremic $4 \mathrm{~d}$ after inoculation, and only a few had sterile blood cultures $(P \leq 0.0001$ for any mutant group vs. the wild-type group). The most striking difference was observed in the E-selectin-deficient mice, $100 \%$ of which remained bacteremic or died. Positive blood cultures in all the selectin-deficient groups consistently showed a higher colony count than those in the

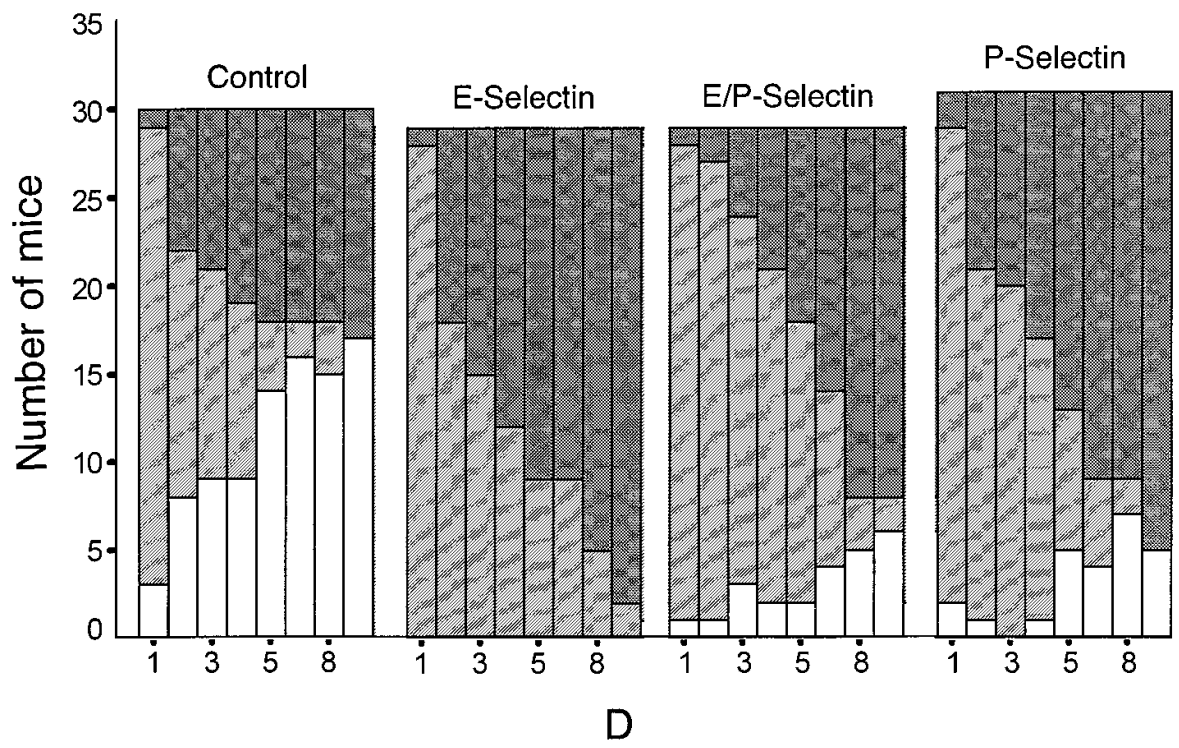

Figure 2. Clearance of bacteremia after intraperitoneal inoculation with S. pneumoniae. Bars, Mice that were alive without bacteremia (white), alive with bacteremia (light gray), or dead (dark gray). A significant difference in the clearance of bacteria from the bloodstream is observed in all selectin-deficient groups vs. the wild-type group ( $P \leq 0.0001$ for each group) throughout the period of observation. 


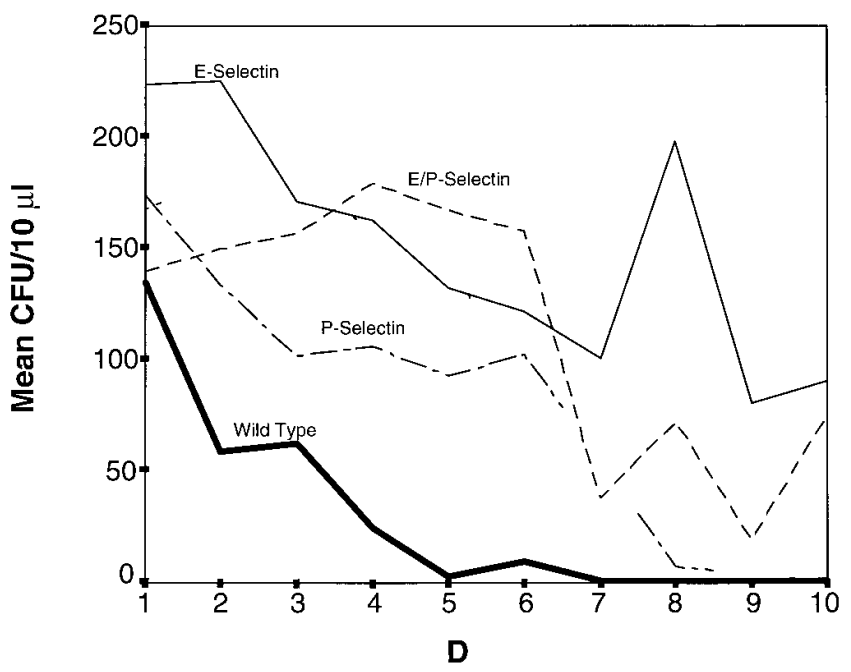

Figure 3. Bacterial load (mean CFU per 10 microliters) in wild-type and selectin-deficient mice after $S$. pneumoniae infection. In all selectin-deficient groups, a higher colony count is observed versus wildtype mice (*P $\leq 0.0001$ for each group). Wild-type, heavy solid line. $\mathrm{E}$-selectin, solid line. E-/P-selectin, dashed line. $\mathrm{P}$-selectin, dashed and dotted line. For each time point, $n=$ number of mice alive with bacteremia from Fig. 2.

wild-type group $(P \leq 0.0001$ for any mutant group vs. the wildtype group) (Fig. 3).

Peripheral $W B C$ count and $A N C$. Before inoculation, the E-/P-selectin-deficient mice showed peripheral leukocytosis (threefold) and neutrophilia when compared with wild-type mice. E- and P-selectin-deficient mice also had mildly elevated peripheral leukocyte counts (1.6- and 1.9-fold, respectively) and mild neutrophilia (Table II). In all groups, the total WBC count and ANC dropped substantially in the first $24 \mathrm{~h}$ after $S$. pneumoniae inoculation (54\% decrease in controls, 33-46\% in selectin-deficient mice), and increased gradually after $48 \mathrm{~h}$.

Analysis of peritoneal fluid and CSF. At $48 \mathrm{~h}$ after inoculation, no significant differences were observed in the total number of leukocytes and neutrophils present in the peritoneal fluid of any of the selectin-deficient mice when compared with wild-type mice (Fig. 4). Neutrophils represented $82 \%$ of the peritoneal fluid leukocytes in the control group, but only $54 \%$ in the E-selectin $(P=0.14)$, and $62-64 \%$ in the E-/P- and P-selectin-deficient mice ( $P=0.08$ and $P=0.56$, respectively). Significant differences were observed when the number of perito-

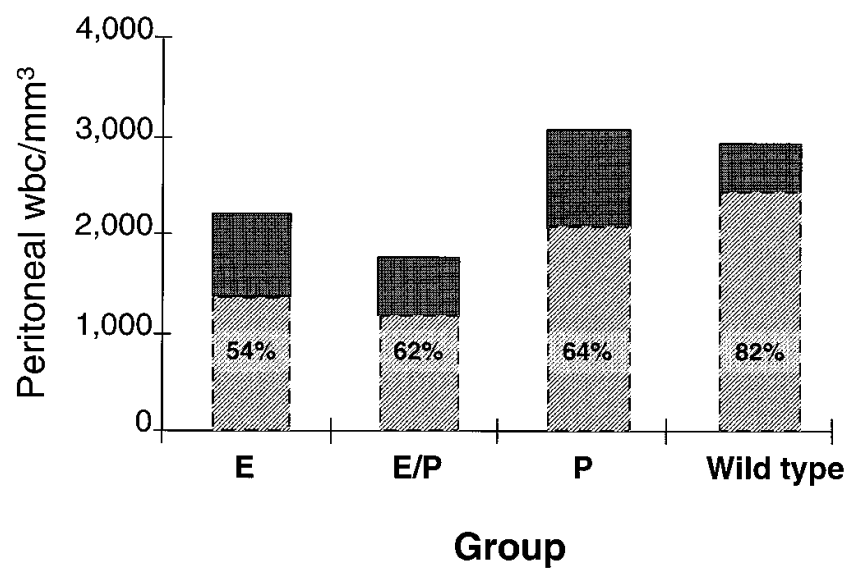

Figure 4. Mean peritoneal fluid WBC cell count per cubic millimeter (solid bar) and mean ANC per cubic millimeter (hatched bar) $48 \mathrm{~h}$ after intraperitoneal inoculation of S. pneumoniae in E- $(n=5)$, E-/P$(n=7)$, P-selectin-deficient $(n=10)$, and wild-type $(n=20)$ mice.

The percentage of neutrophils is represented within the hatched bars.

neal leukocytes collected in a standardized volume of $1 \mathrm{ml}$ was compared with the peripheral leukocyte count within each group. The peritoneal WBC count was only $17.6 \%$ of the peripheral for E-/P-selectin-deficient mice compared with 132, 77, and $93 \%$ in the wild-type, E-, and P-selectin-deficient groups, respectively $(P \leq 0.05)$, suggesting decreased migration into the peritoneum in the double mutants. Similarly, peritoneal fluid neutrophils represented only $13 \%$ of the peripheral ANC in the E-/P-selectin-deficient mice compared with 199, 121, and 79\% in the wild-type, E-, and P-selectin-deficient mice, respectively $(P \leq 0.05)$.

In a small number of animals where CSF was studied $(n=$ 2-7 per group), no significant differences were observed among the groups in the number of positive cultures, WBC count, or percentage of neutrophils in the CSF at $48 \mathrm{~h}$ (data not shown).

Histopathology. The most remarkable histopathological effects of $S$. pneumoniae systemic infection were noted in the spleen and liver of all selectin-deficient mice (Table III). Areas of splenic thrombosis were present in 4/22 (18\%) wild-type mice, but were more frequent in P- $(9 / 13$ or $69 \%)$ and E-selectin $(4 / 5$ or $80 \%)$-deficient mice $(P=0.004$ and $P=0.017$, respectively) (Figs. 5 and 6). Similarly, splenic necrosis was more common in P-selectin-deficient mice $(5 / 13$ or $38 \%)$ than in wild-type mice $(1 / 22$ or $5 \%)(P=0.02)$, but was not observed in E-selectin-deficient mice. Double mutants presented lesser

Table II. Mean Peripheral Leukocyte Count and Percentage of Neutrophils of Wild-Type and Endothelial Selectin-deficient Mice at Different Times after S. pneumoniae Inoculation

\begin{tabular}{|c|c|c|c|c|c|c|c|c|}
\hline \multirow[b]{2}{*}{ Time } & \multicolumn{2}{|c|}{ Wild-type $(n=30)$} & \multicolumn{2}{|c|}{ E-selectin-deficient $(n=29)$} & \multicolumn{2}{|c|}{ P-selectin-deficient $(n=31)$} & \multicolumn{2}{|c|}{ E-/P-selectin-deficient $(n=29)$} \\
\hline & $\mathrm{WBC}^{*}$ & PMN & WBC & PMN & WBC & PMN & WBC & PMN \\
\hline$h$ & & $\%$ & & $\%$ & & $\%$ & & $\%$ \\
\hline 0 & $7045 \pm 2180$ & 42 & $13454^{\ddagger} \pm 2287$ & 34 & $11421^{\ddagger} \pm 1831$ & 46 & $21804^{\ddagger} \pm 6137$ & $59^{\ddagger}$ \\
\hline 24 & $4282 \pm 776$ & 56 & $4212 \pm 1098$ & 57 & $5293 \pm 2466$ & $70^{\ddagger}$ & $8900^{\ddagger} \pm 3859$ & $82^{\ddagger}$ \\
\hline 48 & $6186 \pm 3884$ & 68 & $4786 \pm 2251$ & 62 & $5766 \pm 2923$ & $97^{\ddagger}$ & $16093^{\ddagger} \pm 6027$ & $97^{\ddagger}$ \\
\hline
\end{tabular}

*Values are expressed as mean \pm SD. ${ }^{*} P \leq 0.05$ vs. wild-type mice. 
Table III. Results of Histopathologic Examination of Spleen, Liver, and Brain in Wild-Type and Selectin-deficient Mice $48 \mathrm{~h}$ after Intraperitoneal Inoculation with S. pneumoniae

\begin{tabular}{lcccc}
\hline & $\begin{array}{c}\text { Wild-type } \\
(n=22)\end{array}$ & $\begin{array}{c}\text { P-selectin } \\
(n=13)\end{array}$ & $\begin{array}{c}\text { E-/P-selectin } \\
(n=7)\end{array}$ & $\begin{array}{c}\text { E-selectin } \\
(n=5)\end{array}$ \\
\hline & \multicolumn{5}{c}{$\%$ positive } \\
Spleen & \multicolumn{4}{c}{} \\
Necrosis & 5 & $38^{*}$ & 29 & 0 \\
Thrombi & 18 & $69^{\ddagger}$ & $57^{\S}$ & $80^{\|}$ \\
PMN & 82 & 100 & 100 & 100 \\
Capsular PMN & 82 & 62 & 100 & 80 \\
Liver & & & & \\
Necrosis & 32 & $77^{\Uparrow}$ & $71^{* *}$ & 80 \\
Thrombi & 9 & 23 & 14 & 0 \\
Aggregates & 64 & 85 & 43 & 60 \\
Periportal PMN & 41 & 62 & 71 & 0 \\
Circulating PMN & 14 & 23 & 71 & 20 \\
Brain & & & & \\
Meningitis & 41 & 31 & 85 & 60 \\
PMN & 10 & 0 & 29 & 0 \\
Abscess & 23 & 8 & 29 & 40 \\
& & & & \\
\hline
\end{tabular}

${ }^{*} P=0.021 .{ }^{\ddagger} P=0.004 .{ }^{\mathbb{T}} P=0.015 . \| P=0.017 .{ }^{\S} P=0.068 . * * P=0.092$ (vs. wild-type mice for all $P$ values).

degrees of thrombosis and necrosis in the spleen. There were no differences in inflammation of the splenic parenchyma among the groups, but the degree of neutrophil infiltration was greatest in the E-/P-selectin-deficient mice. In all groups, neutrophils were seen in the capsule of the spleen, suggesting peritonitis.

Similarly, hepatic necrosis was observed in 7/22 (32\%) wildtype mice, and although present in all selectin-deficient animals, it was more common in P-selectin-deficient mice (10/13 or $77 \%)(P=0.01)$ (Fig. 7). Areas of hepatic necrosis were evident by macroscopic examination in the P-selectin-deficient group only. Microscopically, neutrophil infiltration surrounding the

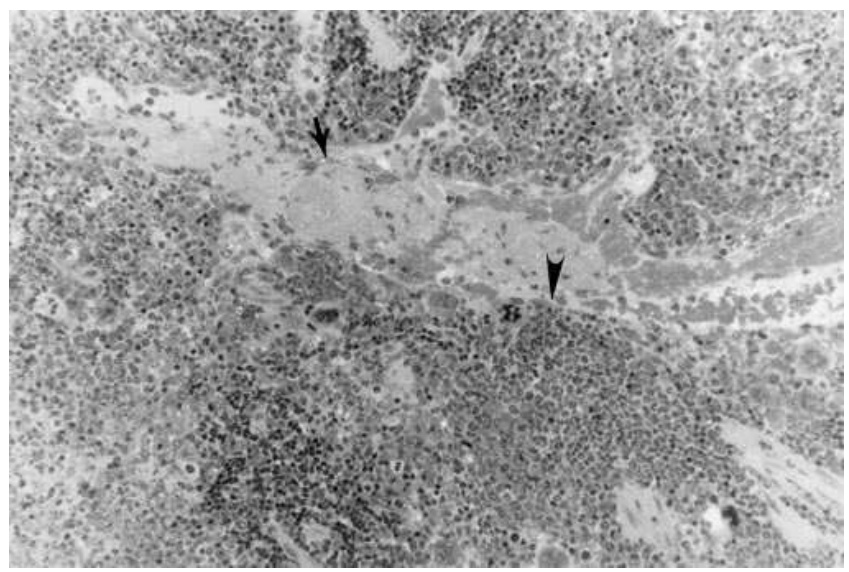

Figure 5. Several portions of an organizing fibrin thrombus (arrow) are noted in this spleen from a P-selectin-deficient mouse infected with $S$. pneumoniae. Large clusters of polymorphonuclear leukocytes (arrowhead) are scattered throughout the splenic parenchyma. Hematoxylin and eosin; $\times 160$, original magnification.

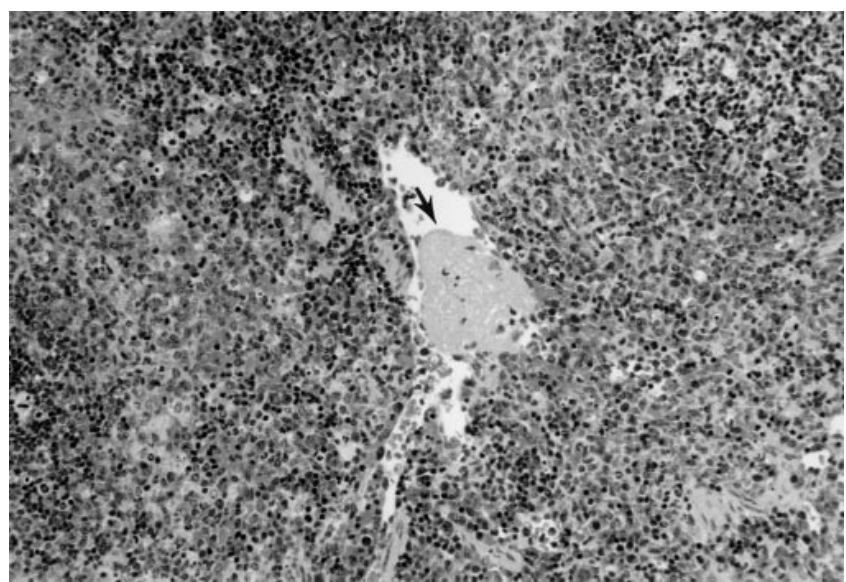

Figure 6. An organizing fibrin thrombus (arrow) is present in this spleen from an E-selectin-deficient mouse infected with $S$. pneumoniae. Occasional polymorphonuclear leukocytes are noted within the splenic parenchyma. Hematoxylin and eosin; $\times 160$, original magnification.

areas of necrosis was present in all the E-/P-, and in $>60 \%$ of the P- and E-selectin-deficient mice. Thrombi were less frequent but were present in the liver of a small number of wildtype, E-/P-, and P-selectin-deficient mice. Circulating neutrophils and leukocyte aggregates were present in all groups. There was mild periportal inflammation in all groups, except the E-selectin-deficient mice.

No significant differences were observed in the histopathology of the brain. Meningitis was present in $40-85 \%$ of all the animals, and brain parenchymal abscess formation was noted in all groups (Table III). Areas of bacterial invasion of the brain parenchyma without neutrophil accumulation were observed in one P-, and one E-/P-selectin-deficient mouse each.

The kidneys showed mild pathologic changes in a few animals, but no thrombosis. Intraparenchymal abscesses were found in 2/5 (40\%) E-selectin-deficient mice. One P-selectin-

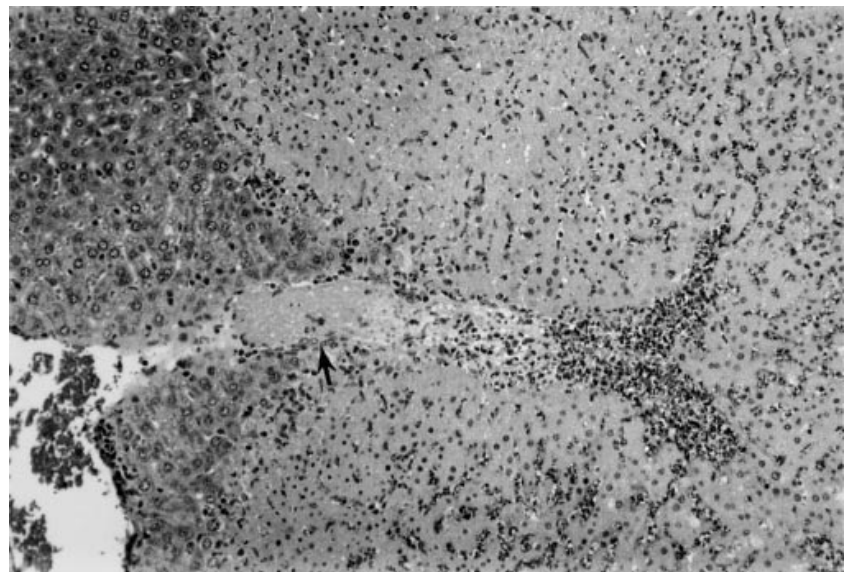

Figure 7. An organizing fibrin thrombus (arrow) is present at the edge of a large area of necrosis in this liver from a P-selectin-deficient mouse infected with $S$. pneumoniae. Large numbers of polymorphonuclear leukocytes are present at the edges and within the sinusoids in the necrotic tissue. Hematoxylin and eosin; $\times 160$, original magnification. 
deficient mouse $(n=13)$ showed multiple renal abscesses, venous thrombi, and bacteria. Only mild interstitial inflammation was present in the kidneys of one E-/P- $(n=13)$, one P-selectin-deficient, and one wild-type mouse $(n=22)$ each. Necrotic tubules with abundant bacteria were observed in one wild-type animal.

\section{Discussion}

Our results provide evidence that leukocyte and endothelial cell adhesion molecules are important for the host defense against bacterial infection, and support the conclusion that the absence of endothelial selectin molecules results in an impaired host response to systemic pneumococcal infection. After inoculation with $S$. pneumoniae, mice genetically deficient in one or both endothelial selectins showed more prominent morbidity, substantially increased mortality, persistent bacteremia, and a higher bacterial load compared with wild-type mice. These results, along with observations of increased susceptibility to infections in patients with leukocyte adhesion deficiency syndromes types I and II, provide clear evidence of the importance of integrins and selectins, respectively, in the host defense against bacterial infection (26).

The course of $S$. pneumoniae infection has been described previously in wild-type and other adhesion molecule-deficient mice. A deficiency of ICAM-1 or ICAM-1/CD18 molecules in mice results in significant morbidity and mortality in response to intraperitoneal injection of $S$. pneumoniae $(27,28)$. Similarly, mice deficient in integrin-associated protein demonstrate an increased mortality after Escherichia coli infection (29). In this study, mice with E- or P-selectin deficiencies show a significant increased mortality compared with wild-type mice after inoculation with $S$. pneumoniae, suggesting that the absence of endothelial selectin molecules is detrimental to the host's response to gram-positive sepsis. It is likely that deficiencies of leukocyte and endothelial cell adhesion molecules will lead ordinarily to increased susceptibility to bacterial infection; however, considerable variation may exist, depending on the adhesion molecules and the specific organisms involved.

There are examples of genetic deficiencies in leukocyte and endothelial cell adhesion molecules in mice that lead to an apparent beneficial result, as in the case of greater early survival after Haemophilus influenzae or gram-negative infection in mice deficient in ICAM-1 or both ICAM-1 and CD18 molecules $(27,28,30)$. It is probable that this beneficial effect is due to resistance to the harmful effects of endotoxin in these mutant mice. This may represent a normal or increased susceptibility to infection balanced by protection against some of the toxic inflammatory responses caused by the infection itself. It is unclear if the slightly increased early survival (0-5 d) observed in E-/P-selectin-deficient mice in this study represents a similar example. This beneficial effect was small, and the final outcome was poor compared with wild-type mice, although better than for either selectin deficiency alone. It is possible that the presence of persistently high numbers of circulating leukocytes and plasma cells, and higher serum levels of immunoglobulins in the E-/P-selectin-deficient mice provides them with a state that is advantageous for their initial response to pneumococcal sepsis, but detrimental for prolonged survival after untreated infection. Similarly, although we observed higher baseline peripheral leukocyte and neutrophil counts than reported previously in wild-type mice and single mutants, the counts were similar to those of wild-type mice after $24 \mathrm{~h}$. Higher baseline peripheral counts present in all groups may be related to environmental factors such as husbandry, age, or stress, or to factors associated with the site and method of blood collection, or methods of WBC-count determinations, and are probably not related to the poor overall outcome of single mutants.

The presence of a significantly higher number of pneumococci isolated from the blood of mice deficient in endothelial selectins provides a possible explanation for the high mortality of these mutants. This is evident particularly in the E-selectindeficient mice, which have the highest mortality paralleled by persistent bacteremia. No obvious phenotype was observed in E-selectin-deficient mice when described initially, and normal neutrophil trafficking was attributed to redundancy in the function of P- and E-selectin molecules (19, 21, 22). Subsequently, a phenotype of impaired slow leukocyte rolling in E-selectin-deficient mice was identified (20). We now demonstrate a significant inflammatory abnormality with increased mortality and persistent bacteremia in E-selectin-deficient mice. It is possible that these findings may be directly related to the alteration of E-selectin-dependent slow leukocyte rolling (20), or may involve more complex interactions whereby E-selectin contributes to the activation of neutrophils, the increased expression of macrophage antigen-1 (CD11b/CD18) integrin (31), and increased chemoattractant activity (32). These results suggest a possible role for E-selectin in neutrophil activation. Similarly, mice with double E-/P-selectin deficiency would be expected to have suboptimal neutrophil function. We suggest that an apparently normal phenotype in genetically altered mice may more often be explained by inadequate ability to assess the phenotype than by redundant biological functions, particularly when the function of highly evolutionary conserved molecules has been disrupted.

When comparing these results with clinical approaches for the treatment of bacterial sepsis, it is important to distinguish the role of inflammatory responses in eliminating bacteria from inflammatory processes that may lead to secondary harmful effects during septic shock. The loss of leukocyteendothelial interactions is likely to be uniformly detrimental for the clearance of bacteremia. However, blocking cell adhesion molecules may be beneficial in blunting detrimental inflammatory responses during sepsis, particularly if bacteremia can be controlled with antibiotics. Thus, clinical attempts to use mAbs to E-selectin to reverse gram-negative shock (33) have the potential risk of impairing the host response to bacteremia, but the potential benefit of blunting a detrimental inflammatory response, and the net effect can only be judged by carefully designed clinical trials. Furthermore, the increased mortality observed in all of the selectin-deficient mice studied emphasizes that these molecules are evolutionarily important for host defense against infection.

In E-, P-, and E-/P-selectin-deficient mice, the number of leukocytes and neutrophils in the peritoneal cavity at $48 \mathrm{~h}$ after $S$. pneumoniae infection was not decreased significantly compared with wild-type mice. These findings are consistent with those of other investigators. Leukocyte emigration to the peritoneal cavity has been found to be impaired in $\mathrm{P}$ - and $\mathrm{E}-\mathrm{P}$ selectin-deficient mice at early time points $(2-4 \mathrm{~h})$ after chemical or bacterial peritonitis $(15,18,21,22)$, or normal to increased in these same models at later times $(24-48 \mathrm{~h})(15,16,21)$. Emigration is normal at $4 \mathrm{~h}$ in rabbits with $E$. coli peritonitis 
treated with anti-P-selectin mAbs (34). E-selectin-deficient mice have not been shown to have an impairment of leukocyte emigration to the peritoneum at any time $(19,21,22)$. Our findings suggest further the existence of alternative mechanisms for initiating leukocyte migration to this site. Possible alternative mechanisms may include L-selectin-mediated interactions (35, 36), CD18-dependent leukocyte rolling and subsequent adhesion in stimulated postcapillary venules at lower shear rates during sepsis (37), and pathogen-specific interactions such as leukocyte migration induced by $S$. pneumoniae cell wall components (38).

Histopathologic studies also confirmed considerable capacity for leukocyte emigration into organ tissues in these animals, showing inflammatory changes and abscess formation in both wild-type and mutant mice. Similarly, a drop in peripheral leukocyte counts observed $24 \mathrm{~h}$ after inoculation in all groups is suggestive of effective leukocyte migration to tissues in response to disseminated bacterial infection. Minimal numbers of bacteria were seen in organ tissues of wild-type and mutant mice, indicating appropriate clearance of bacteria by tissue defense mechanisms. At $48 \mathrm{~h}$ after infection, there was no evidence of impairment of leukocyte migration into the CSF in a small group of selectin-deficient animals. Mice deficient in $\mathrm{P}$ - and particularly E-/P-selectins have been shown to have a partial reduction of CSF leukocyte influx at earlier times $(2-6 \mathrm{~h})$ in a cytokine-induced model of meningitis, but this difference is not evident at $24 \mathrm{~h} \mathrm{(39)}$. A larger number of mice might be needed to observe differences in our model, or a distinct response is preserved during bacterial meningitis at the specific time point of $48 \mathrm{~h}$.

P-selectin-deficient mice showed increased incidence of liver and spleen necrosis and spleen thrombosis. Splenic thrombosis was also present in the E-selectin-deficient group. The mechanism of enhanced thrombogenesis in P- and E-selectindeficient mice is unclear. Mice with E-, P-, and E-/P-selectin deficiencies have no alterations in the number of circulating platelets $(22,40)$. P-selectin is important in platelet and leukocyte interactions during thrombus formation and fibrin deposition in vivo $(13,14,41)$, and P-selectin deficiency is associated with prolonged bleeding time in mice (40). Alternate pathways leading to thrombogenesis may include platelet activation by neutrophil-derived products $(42,43)$, platelet-activating factor-stimulated platelet-leukocyte interactions (44), and neutrophil activation through CD11/CD18 mechanisms $(45,46)$. Pneumococci binding to endothelial cells activate the procoagulant cascade by enhancing the production of platelet-activating factor, which recruits platelets and leukocytes to infected tissues (47-49). CD18-dependent leukocyte aggregation could induce tissue damage if aggregation is sufficient to cause vascular occlusion and subsequent ischemia (50). It is possible that thrombogenesis occurs by any of these alternative mechanisms in wild-type and selectin-deficient mice.

In summary, our findings suggest that E- and P-selectinmediated rolling plays an important role in the host defense mechanisms against $S$. pneumoniae infection, and that the function of these two molecules is not entirely redundant. The results of this study also provide evidence of an inflammatory impairment in E-selectin-deficient mice. Although the blockade of both endothelial selectin molecules could offer potential benefit early during sepsis due to gram-positive organisms, a prolonged blockade appears to be detrimental for outcome. Further study of the role of selectin molecules in the pathogen- esis of S. pneumoniae and other bacterial infections is warranted.

\section{Acknowledgments}

The authors acknowledge Edward O. Mason, Jr., Rebekah Lichenstein, and Linda Lambert for assistance in performing the experiments; Leigh Ann Hurley for technical assistance genotyping the mice; E. O'Brian Smith for help with the statistical analysis; and C. Wayne Smith for reviewing the manuscript.

We also acknowledge the support from National Institutes of Health grants AI-32177 and GM-15483.

\section{References}

1. Springer, T.A. 1994. Traffic signals for lymphocyte recirculation and leukocyte emigration: the multistep paradigm. Cell. 76:301-314.

2. Tedder, T.F., D.A. Steeber, A. Chen, and P. Engel. 1995. The selectins: vascular adhesion molecules. FASEB (Fed. Am. Soc. Exp. Biol.) J. 9:866-873.

3. Bevilacqua, M.P., and R.M. Nelson. 1993. Selectins. J. Clin. Invest. 91: 379-387.

4. Rosen, D.S. 1993. Cell surface lectins in the immune system. Semin. Immunol. 5:237-247.

5. Bullard, D.C., and A.L. Beaudet. 1997. Analysis of selectin deficient mice. In The Selectins: Initiators of Leukocyte Endothelial Adhesion. D. Vestweber, editor. Harwood Academic Publishers, Münster, Germany. 133-142.

6. Kansas, G.S. 1996. Selectins and their ligands: current concepts and controversies. Blood. 88:3259-3287.

7. Gallatin, W.M., I.L. Weissman, and E.C. Butcher. 1983. A cell-surface molecule involved in organ-specific homing of lymphocytes. Nature (Lond.). 304:30-34.

8. Ley, K., T.F. Tedder, and G.S. Kansas. 1993. L-selectin can mediate leukocyte rolling in untreated mesenteric venules in vivo independent of E- or P-selectin. Blood. 82:1632-1638.

9. Bevilacqua, M.P., J.S. Pober, D.L. Mendrick, R.S. Cotran, and M.A. Gimbrone, Jr. 1987. Identification of an inducible endothelial-leukocyte adhesion molecule. Proc. Natl. Acad. Sci. USA. 84:9238-9243.

10. Olofsson, A.M., K.E. Arfors, L. Ramezani, B.A. Wolitzky, E.C. Butcher, and U.H. von Andrian. 1994. E-selectin mediated leukocyte rolling in interleukin-1-treated rabbit mesentery venules. Blood. 84:2749-2758.

11. Geng, J.C., M.P. Bevilacqua, K.L. Moore, T.M. McIntyre, S.M. Prescott, J.M. Kim, G.A. Bliss, G.A. Zimmerman, and R.P. McEver. 1990. Rapid neutrophil adhesion to activated endothelium mediated by GMP-140. Nature (Lond.). 343:757-760.

12. Larsen, E., A. Celi, G.E. Gibert, B.C. Furie, J.K. Erban, R. Bonfanti, D.D. Wagner, and B. Furie. 1989. PADGEM protein: a receptor that mediates the interaction of activated platelets with neutrophils and monocytes. Cell. 59: 305-312.

13. Palabrica, T., R. Lobb, B.C. Furie, M. Aronovitz, C. Benjamin, Y.-M. Hsu, S.A. Sajer, and B. Furie. 1992. Leukocyte accumulation promoting fibrin deposition is mediated in vivo by P-selectin on adherent platelet. Nature (Lond.). 359:848-851.

14. Furie, B., and B.C. Furie. 1995. The molecular basis of platelet and endothelial cell interaction with neutrophils and monocytes: role of P-selectin and the P-selectin ligand, PSGL-1. Thromb. Haemostasis. 74:224-227.

15. Mayadas, T.N., R.C. Johnson, H. Rayburn, R.O. Hynes, and D.D. Wagner. 1993. Leukocyte rolling and extravasation are severely compromised in $\mathrm{P}$ selectin-deficient mice. Cell. 74:541-554.

16. Johnson, R.C., T.N. Mayadas, P.S. Frenette, R.E. Mebius, M. Subramaniam, A. Lacasce, R.O. Hynes, and D.D. Wagner. 1995. Blood cell dynamics in P-selectin-deficient mice. Blood. 86:1106-1114.

17. Ley, K.E., D. Bullard, M.L. Arbones, R. Bosse, D. Vestweber, T.F. Tedder, and A.L. Beaudet. 1995. Sequential contribution of L- and P-selectin to leukocyte rolling in vivo. J. Exp. Med. 181:669-675.

18. Bullard, D.C., L. Qin, I. Lorenzo, W.M. Quinlin, N.A. Doyle, R. Bosse, D. Vestweber, C.M. Doerschuk, and A.L. Beaudet. 1995. P-selectin/ICAM-1 double mutant mice: acute emigration of neutrophils into the peritoneum is completely absent but is normal into pulmonary alveoli. J. Clin Invest. 95:17821788 .

19. Labow, M.A., C.R. Norton, J.M. Rumberger, K.M. Lombard-Gillooly, D.J. Shuster, J. Hubband, R. Bertko, P.A. Knaas, R.W. Terry, M.L. Harbison, et al. 1994. Characterization of E-selectin-deficient mice: demonstration of overlapping function of the endothelial selectins. Immunity. 1:709-720.

20. Kunkel, E.J., and K. Ley. 1996. Distinct phenotype of E-selectin-deficient mice. E-selectin is required for slow leukocyte rolling in vivo. Circ. Res. 79:1196-1204

21. Bullard, D.C., E.J. Kunkel, H. Kubo, M.J. Hicks, I. Lorenzo, N.A. Doyle, C.M. Doerschuk, K. Ley, and A.L. Beaudet. 1996. Infectious susceptibil- 
ity and severe deficiency of leukocyte rolling and recruitment in E-selectin and P-selectin double mutant mice. J. Exp. Med.183:2329-2336.

22. Frenette, P.S., T.N. Mayadas, H. Rayburn, R.O. Hynes, and D.D. Wagner. 1996. Susceptibility to infection and altered hematopoiesis in mice deficient in both P- and E-selectins. Cell. 84:563-574.

23. Luscinskas, F.W., H. Ding, and A.H. Lichtman. 1995. P-selectin and VCAM-1 mediate rolling and arrest, respectively, of CD4 T-lymphocytes on TNF- $\alpha$-activated vascular endothelium under flow. J. Exp. Med. 181:1179-1186.

24. Dore, M., R.J. Korthuis, D.N. Granger, M.L. Entman, and C.W. Smith. 1993. P-selectin mediates spontaneous leukocyte rolling in vivo. Blood. 82: 1308-1316.

25. Staite, N.D., J.M. Justen, L.M. Sly, A.L. Beaudet, and D.C. Bullard. 1996. Inhibition of delayed type contact hypersensitivity in mice deficient in both E-selectin and P-selectin. Blood. 88:2973-2979.

26. Anderson, D.C. T.K. Kishimoto, and C.W. Smith. 1995. Leukocyte adhesion deficiency and other disorders of leukocyte adherence and motility. In The Metabolic and Molecular Bases of Inherited Disease. C.R. Scriver, A.L. Beaudet, W.S. Sly, and D. Valle, editors. McGraw-Hill Inc., New York. 39553994.

27. Tan, T.Q., C.W. Smith, E.P. Hawkins, E.O. Mason, Jr., and S.L. Kaplan. 1995. Hematogenous bacterial meningitis in an intercellular adhesion molecule1-deficient infant mouse model. J. Infect. Dis. 171:342-349.

28. Tan, T.Q., C.W. Smith, E.P. Hawkins, and S.L. Kaplan. 1995. Differential survival in ICAM-1/CD18 deficient double mutant infant mice infected with Haemophilus influenzae type b or Streptococcus pneumoniae. Pediatr. Res. 37 (Part 2):11A. (Abstr.)

29. Lindberg, F.P., D.C. Bullard, T.E. Carver, H.D. Gresham, A.L. Beaudet, and E.J. Brown. 1996. Decreased resistance to bacterial infection and granulocyte defects in IAP-deficient mice. Science (Wash. DC). 274:795-798.

30. Xu, H., J.A. Gonzalo, Y. St. Pierre, I.R. Williams, T.S. Kupper, R.S. Cortan, T.A. Springer, and J.C. Gutierrez-Ramos. 1994. Leukocytosis and resistance to septic shock in intercellular adhesion molecule 1-deficient mice. J. Exp. Med. 180:95-109.

31. Araki, M., K. Araki, Y. Miyazaki, M. Iwamoto, S. Izui, K.-I. Yamamura, and P. Vassalli. 1996. E-selectin binding promotes neutrophil activation in vivo in E-selectin transgenic mice. Biochem. Biophys. Res. Commun. 224:825-830.

32. Lo, S.K., S. Lee, R.A. Ramos, R. Lobb, M. Rosa, G. Chi-Rosso, and S.D. Wright. 1991. Endothelial-leukocyte adhesion molecule 1 stimulates the adhesive activity of leukocyte integrin CR3 (CD11b/CD18, Mac-1, $\alpha \mathrm{m} \beta 2$ ) on human neutrophils. J. Exp. Med. 173:1493-1500.

33. Friedman, G., S. Jankowski, M. Shahla, M. Goldman, R.M. Rose, R.J. Kahn, and J.-L. Vincent. 1996. Administration of an antibody to E-selectin in patients with septic shock. Crit. Care Med. 24:229-233.

34. Sharar, S.R., S.S. Sasaki, L.C. Flaherty, J.C. Paulson, J.M. Harlan, and R.K. Winn. 1993. P-selectin blockage does not impair leukocyte host defense against bacterial peritonitis and soft tissue infection in rabbits. J. Immunol. 151: 4982-4988.

35. Tedder, T.F., and P. Pizcueta. 1995. L-selectin-deficient mice have im- paired leukocyte recruitment into inflammatory sites. J. Exp. Med. 181:22592264

36. Sharar, S.R., N.N. Chapman, L.C. Flaherty, J.M. Harlan, T.F. Tedder, and R.K. Winn. 1996. L-selectin (CD621) blockade does not impair peritoneal neutrophil emigration or subcutaneous host defense to bacteria in rabbits. $J$. Immunol. 157:2555-2563.

37. Gaboury, J.P., and P. Kubes. 1994. Reductions in physiologic shear rates lead to CD11/CD18-dependent, selectin-independent leukocyte rolling in vivo. Blood. 83:345-350.

38. Mileski, W., J. Harlan, C. Rice, and R. Winn. 1990. Streptococcus pneumoniae-stimulated macrophages induce neutrophils to emigrate by a CD18independent mechanism of adherence. Circ. Shock. 31:259-267.

39. Tang, T., P.S. Frenette, R.O. Hynes, D.D. Wagner, and T.N. Mayadas. 1996. Cytokine-induced meningitis is dramatically attenuated in mice deficient in endothelial selectins. J. Clin. Invest. 97:2485-2490.

40. Subramaniam, M., P.S. Frenette, S. Saffaripour, R.C. Johnson, R.O. Hynes, and D.D. Wagner. 1996. Defects in hemostasis in P-selectin-deficient mice. Blood. 87:1238-1242.

41. Kuijper, P.H.M., H.I.G. Torres, J.A.M. van der Linden, J.-W.J. Lammers, J.J. Sixma, L. Koenderman, and J.J. Zwaginga. 1996. Platelet-dependent primary hemostasis promotes selectin and integrin-mediated neutrophil adhesion to damaged endothelium under flow conditions. Blood. 87:3271-3281.

42. Clark, R.A., and S.J. Klebanoff. 1980. Neutrophil-platelet interaction mediated by myeloperoxidase and hydrogen peroxide. J. Immunol. 124:399-405.

43. Pratico, D., L. Iulano, C. Alessandri, C. Camastra, and F. Violi. 1993. Polymorphonuclear leukocyte-derived $\mathrm{O}_{2}$-reactive species activate primed platelets in human whole blood. Am. J. Physiol. 264:H1582-H1587.

44. Lorant, D.E., K.D. Patel, T.M. McIntyre, R.P. McEver, S.M. Prescott, and G.A. Zimmerman. 1991. Coexpression of GMP-140 and PAF by endothelium stimulated by histamine or thrombin: a juxtacrine system for adhesion and activation of neutrophils. J. Cell Biol. 115:223-234.

45. Zimmerman, G.A., S.M. Prescott, and T.M. McIntyre. 1992. Endothelial cell interactions with granulocytes: tethering and signaling molecules. Immunol. Today. 13:93-100.

46. Lorant, D.E., M.K. Topham, R.E. Whatley, R.P. McEver, T.M. McIntyre, S.M. Prescott, and G.A. Zimmerman. 1993. Inflammatory roles of P-selectin. J. Clin. Invest. 92:559-570.

47. Cabellos, C., D.E. MacIntyre, M. Forrest, M. Burroughs, S. Prasad, and E. Tuomanen. 1992. Differing roles for platelet-activating factor during inflammation of the lung and subarachnoid space. J. Clin. Invest. 90:612-618.

48. Geelen, S., C. Bhattacharya, and E. Tuomanen. 1992. Induction of procoagulant activity on human endothelial cells by Streptococcus pneumoniae. Infect. Immun. 60:4179-4183.

49. Tuomanen, E.I., R. Austrian, and H.R. Masure. 1995. Pathogenesis of pneumococcal infection. N. Engl. J. Med. 332:1280-1284.

50. Thomas, J.R., J.M. Harlan, C.L. Rice, and R.K. Winn. 1992. Role of leukocyte CD11/CD18 complex in endotoxic shock and septic shock in rabbits. $J$. Appl. Physiol. 73:1510-1516. 